Aletria, Belo Horizonte, v. 29, n. 3, p. 79-96, 2019

\title{
Contratradições inventadas: crise e fantasmas da Teoria
}

\section{Invented Countertraditions: Theory's Crisis and Ghosts}

\author{
Pedro Henrique Trindade Kalil Auad \\ Universidade Federal de Alagoas (UFAL), Maceió, Alagoas / Brasil \\ pedroauad@gmail.com
}

Resumo: Este artigo parte do conceito de tradições inventadas, cunhado por Eric Hobsbawm e Terence Ranger para pensar sobre a história da Teoria da Literatura e a crise desta que se desenvolve principalmente a partir dos anos 1980. Nesse sentido, nos debruçamos sobre o trabalho de três autores que refletiram sobre a crise, a saber, Terry Eagleton, Vincent B. Leitch e Paul H. Fry. A partir disso, pensamos sobre os postulados da crise da Teoria e suas contradições e como o discurso sobre a crise teórica é um discurso não só interessado, mas também centrado num espaço específico e que representa apenas certos modelos teóricos. Assim, percebemos que a teoria não acabou, e que ela continua assombrada por fantasmas, tendo aqui a concepção destes extraída das reflexões de Jacques Derrida.

Palavras-chave: teoria da literatura; crise; fantasmas; tradução; tradição inventada.

\begin{abstract}
Departing from the notion of invented traditions, coined by Eric Hobsbawm and Terence Ranger, this article reflects about the history of Literature Theory and its crisis that evolves mainly from the 1980s. In this sense, we focus on the work of three authors who weigh in on these subjects, namely, Terry Eagleton, Vincent B. Leitch, and Paul H. Fry. From this, we considered the postulates of the Theory crisis, its contradictions and how the discourse on the theoretical crisis is a discourse not only interested, but also centered in a specific space and represents only certain theoretical models. Thus, we realize that the Theory is not over, and that it remains haunted by ghosts, whose concept was extracted from Jacques Derrida's perspective.
\end{abstract}

Keywords: literary theory; crisis; ghosts; translation; invented traditions. 
Eric Hobsbawm e Terence Ranger denominaram de tradição inventada o "processo de formalização e ritualização, caracterizado por referir-se ao passado, mesmo que apenas pela imposição da repetição." Seria através de repetições de um passado - não necessariamente remoto - que se formaria um novo tipo de tradição. O movimento aqui é mais borgiano do que teleológico: o passado é estabelecido através dessas repetições, apontando um certo grau de invariabilidade, fixando certos tipos de práticas. Assim, teríamos uma prática discursiva, não só teórica, a respeito da teoria. É, portanto, nos discursos sobre a teoria que a tradição inventada começa a se reformular. Mais especificamente, pode-se afirmar que é em um processo de tradução - o discurso sobre a teoria, que a ressignifica - que uma certa tradição inventada é constituída.

Ao longo da história da teoria e da formalização dessa história foram se construindo diversas tradições inventadas. Entretanto, é importante salientar que o discurso sobre as teorias não é inventado, como pode sugerir o conceito de Hobsbawm e Ranger, mas são discursos, em geral, parcializados. Esse discurso é feito a partir de certas traduções dessas teorias e, quando essas teorias são traduzidas, perdem-se alguns aspectos. São esses aspectos perdidos - e os silêncios retóricos esquecidos - que fazem com que essas tradições e filiações produzam discursos interessados e, muitas vezes, parciais, destacando alguns aspectos das teorias em detrimento de outros.

É dessa forma que se constrói o discurso, por exemplo, sobre o Formalismo Russo. É sabido que os estudos literários não começaram com os Formalistas, mas foram eles os eleitos como os inauguradores da teoria literária. Assim, é destacada a ênfase que dão ao objeto literário em detrimento de aspectos extraliterários e a sua ligação com a linguística e, consequentemente, a aproximação com uma espécie de ciência da literatura. Ou seja, a tradição inventada da teoria literária, em um sentido mais "puro", encontraria correspondência na abordagem mais científica, mais centrada em aspectos linguísticos com o foco voltado para a construção da linguagem literária, a literariedade. Alguns aspectos do Formalismo foram elididos da tradição inventada da história da teoria da literatura como a vertente multidisciplinar, e sua dobra sobre o leitor através de um de seus principais conceitos - estranhamento -, por exemplo. Ou seja, o Formalismo entendido pelo senso comum, ou

${ }^{1}$ HOBSBAWM; RANGER. A invenção das tradições, p. 13. 
essa tradição do senso comum, foi uma construção parcializada, mas que serviu como mote para a fixação de uma tradição do que seria chamado de Teoria e, para ressaltar essa dinâmica que tende a apagar os paradoxos e contradições, chamaremos esse processo de contratradição inventada. Enfim, através dessas traduções teóricas se fortalece um sentido de tradição. Não uma tradição imanente da teoria, mas aquilo que se quer traduzido, o que nos leva para a reflexão sobre a crise da teoria, anunciada, ao menos, de forma mais perene, desde os anos 1980.

\section{A crise atual}

É difícil encontrar um consenso a respeito da crise na teoria da literatura. Essas múltiplas interpretações passam tanto pela origem da crise como pelo grupo teórico que ela afetaria. A crise não pode ser entendida uniformemente e, por isso, não se deverá pensar apenas em uma crise, mas em várias crises. Há interpretações sobre a crise de que esta passaria por um problema extrínseco à obra e chegaria à teoria, como a crise do livro na era digital, ${ }^{2}$ mas nos deteremos na discussão sobre o fim/crise/depois da teoria e a sua relação com a contratradição inventada. Elencaremos três dessas premissas: a de Terry Eagleton em Depois da Teoria; as discussões de Leitch em Living with Theory; a seguir, os pressupostos de Paul H. Fry em seu Theory of Literature.

Na primeira delas, Terry Eagleton não elucubra sobre toda a teoria, mas de uma específica, à qual dá o nome de "teoria cultural". Essa teoria cultural perpassaria tanto o estruturalismo, o pós-estruturalismo, quanto os Estudos Culturais. E, já no primeiro parágrafo da sua obra, o filósofo britânico define o corpus dessa teoria cultural:

A idade de ouro da teoria há muito já passou. Os trabalhos pioneiros de Jacques Lacan, Claude Lévi-Strauss, Louis Althusser, Roland Barthes e Michel Foucault ficaram várias décadas atrás. Assim também os inovadores escritos iniciais de Raymond Williams, Luce Irigaray, Pierre Bourdieu, Julia Kristeva, Jacques Derrida, Hélène Cixous, Jurgen Habermas, Frederic Jameson e Edward Said. Não muito do que tem sido escrito desde então é comparável à ambição e originalidade desses precursores. Alguns deles

${ }^{2}$ Cf. CARRIÈRE; ECO. Não contem com o fim do livro. 
foram derrubados. O destino empurrou Roland Barthes para debaixo da caminhonete de uma lavanderia parisiense e vitimou Michel Foucault com a Aids. Despachou Lacan, Williams e Bourdieu e baniu Louis Althusser para um hospital psiquiátrico pelo assassinato de sua esposa. Parecia que Deus não era um estruturalista. ${ }^{3}$

O que Eagleton pretende com o seu livro não é destacar que a teoria se encerrou e acabou, mas afirmar que, enquanto uma nova onda de teóricos não surge no horizonte, estamos lidando com o passado, dado que "se teoria significa uma reflexão razoavelmente sistemática sobre as premissas que nos orientam, ela permanece tão indispensável quanto antes". ${ }^{4}$ Eagleton chega a afirmar também o período histórico em que é encenado o auge da teoria e o seu declínio: a contracultura dos anos 1960 e 1970 e o pós-modernismo dos anos 1980 e 1990. Não entendamos, entretanto, que a teoria acabou, afinal, ela continuou a ser expandida, transformada, questionada e ampliada.

No livro de Eagleton é possível perceber que, mesmo com a perda de certa hegemonia e com tantos questionamentos, o autor argumenta que "não podemos nunca estar 'depois da teoria', no sentido em que não pode haver vida humana reflexiva sem ela. Podemos simplesmente ir esgotando estilos de pensamento particulares à medida que muda nossa situação". 5 Ressalta-se aqui a afirmação de que não se pode estar depois da teoria a não ser que essa teoria seja entendida como um estilo de pensamento particular ou, ainda, poderíamos afirmar, seguindo a lógica de Eagleton, que todo o discurso sobre a crise da teoria é um discurso propriamente teórico: teoriza-se a crise e o fim da teoria.

O teórico inglês está lidando em um terreno extremamente pantanoso, ainda mais quando ele liga essa tradição, que chamou de teoria cultural, à esquerda política e ao marxismo. O movimento de Eagleton é curioso porque liga Saussure e boa parte das teorias mais evidentes do século XX a essa tradição da esquerda. A pós-modernidade e o fim da história seriam, para o filósofo inglês, uma mistura de desilusão stalinista

\footnotetext{
${ }^{3}$ EAGLETON. Depois da teoria, p. 13.

${ }^{4}$ EAGLETON. Depois da teoria, p. 14.

${ }^{5}$ EAGLETON. Depois da teoria, p. 297.
} 
com a ascensão hegemônica de um desenvolvimento teórico de direita. ${ }^{6}$ Enfim, a contratradição inventada de Eagleton é abertamente ideológica e, por meio disso, o autor desenvolve um argumento de que a crise da teoria é um momento de entressafra até o surgimento de novos teóricos culturais que darão conta da complexidade do mundo contemporâneo.

Vicent B. Leitch, em Living With Theory (2008), apresenta outro quadro complexo, comportando definições de o que é a teoria da literatura em uma visão contemporânea e as críticas a essas definições. Primeiramente, a teoria poderia ser entendida como um campo muito amplo que coincidiria, inclusive, com a crítica e a história literária. Essa teoria seria aquela que, ao unir várias outras correntes teóricas, formou um grande campo denominado de "estudos culturais", tendo sido rejeitada por "acadêmicos dedicados à moral de meados do século e por análises formalistas do cânone literário". ${ }^{7}$ Em segundo lugar, Leitch aponta que a teoria poderia ser pensada como princípios gerais para o estudo literário. Contra essa visão, ele afirma que alguns dos outros campos de estudos literários chamaram a atenção para o fato de que a teoria não poderia ter um valor universal. Em terceiro lugar, segundo Leitch, a teoria poderia ser entendida como uma ferramenta que viria a ser julgada pela produtividade e pela inovação. Contra essa versão da teoria estariam aqueles que argumentam que a interpretação totalmente objetiva é impossível. Em quarto lugar, a teoria denotaria um senso comum profissional, mas essa teoria "paradoxalmente termina por diluir sua especificidade, seus conflitos, e suas agendas críticas da sociedade". ${ }^{8}$ Uma quinta possível definição do que seria a teoria pode ser denominada como A Grande Teoria, isto é, o estruturalismo e o pós-estruturalismo e o que viria depois dessas correntes teóricas seria a pós-teoria. Mas essa versão também seria contestada por conservadores e idealistas, nominalistas obscurantistas, marxistas, feministas, pela teoria

${ }^{6}$ Flora Süssekind irá argumentar algo semelhante em A crítica como papel de bala (2013). Depois de certa "dominância de uma cultura de esquerda" (SÜSSEKIND. A crítica como papel de bala, p. 299), a crítica, principalmente depois da morte de Wilson Martins, desenvolveu "reações de ressentimento nostálgico e certo proselitismo agressivamente conservador" (SÜSSEKIND. A crítica como papel de bala, p. 299).

7 "scholars dedicated to mid-century moral and formalist analysis of canonical literary works" (LEITCH. Living with Theory, p. 9-10, tradução minha.)

8 "paradoxically ends up diluting its specificity, its conflicts, and its socially critical agendas" (LEITCH. Living with Theory, p. 10, tradução minha.) 
crítica de raça e pelos estudos culturais. $\mathrm{O}$ autor nota também que o pósestruturalismo ainda está em voga nos estudos literários, constatando dois desdobramentos: a expansão da hegemonia pós-estruturalista e os conflitos éticos e políticos que o pós-estruturalismo enfrentou, como a descoberta de textos antissemitas de Paul de Man. Em sexto lugar, o autor norte-americano aponta que a teoria pode ser pensada como uma forma pós-moderna de discurso que alargaria fronteiras, misturando crítica, filosofia, história, sociologia, psicanálise e política. Em suma, seria o pastiche combatido pelos próprios pós-modernos que minaria a autonomia conquistada pelas teorias na modernidade.

Uma primeira questão que podemos extrair dessa breve descrição das possibilidades de definição semântica de teoria, segundo Leitch, é que um determinado significado sempre se constrói em relação a algum outro. Em outras palavras, é possível inferir que uma teoria sempre é constituída a partir de o que não seria teoria. Uma teoria "conservadora" irá construir identidade em relação aos estudos culturais, por exemplo, ou uma teoria que se pretende mais científica ou objetiva vai se constituir contra aqueles que argumentam que a imparcialidade dos estudos literários não passaria de uma falácia.

Uma segunda observação advém da anterior: Leitch não chega a colocar nesses termos, mas fica óbvio que a definição de teoria passaria por uma disputa entre entendimentos de diversos campos dos estudos literários, já que, para toda definição, Leitch aponta aquele grupo que seria contrário a ela. Aqui, coloca-se a construção da contratradição inventada de maneira muito distinta à de Eagleton, isto é, pela separação entre estruturalistas, críticos culturais, feministas e pós-estruturalistas que, para o autor de Depois da Teoria, estariam todos sob o guarda-chuva da "teoria cultural". E possível observar como a contratradição inventada é uma construção que nem sempre segue a mesma lógica, mas, por outro lado, há uma disputa pelos teóricos eminentes do século XX para que cada uma pertença a uma tradição, sendo que muitos deles participam de mais de uma. Enfim, Barthes talvez seja paradigmático nesse sentido, pois pertence tanto à "teoria cultural", identificada por Eagleton, quanto à tradição. Enfim, esse Barthes poderia ou não pertencer aos "estudos culturais" - termo de Leitch - ou à "teoria cultural" - termo de Eagleton - ou aos "estudos formalistas" que se inspirariam no estruturalismo. Porém, Leitch também irá afirmar que a teoria acabou - que só pode haver um depois da teoria - se temos por definição de teoria apenas o 
pós-estruturalismo. Mas, ressalta o autor, vários aspectos dessa teoria ainda permaneceriam e continuariam a ser úteis.

O autor, contudo, se mostra bastante otimista ao afirmar que tendo a teoria um passado, ela teria também um futuro. Leitch irá clamar por uma continuidade da teoria, isto é, afirma que a teoria, só por ter um passado, encaminharia um sentido de futuro. Em outras palavras, o autor aposta em um sentido teleológico da teoria. A diferença dele, em relação à Eagleton, é que este acredita que ainda se terá uma teoria porque todo o pensamento de depois da teoria ainda é circunscrito por um discurso que é, também, teórico, enquanto Leitch irá contornar essa questão de outra maneira: uma aposta na continuidade imanente da narrativa teórica.

Já Paul H. Fry, em Theory of Literature, irá seguir um caminho diverso de Leitch e Eagleton. O teórico literário inglês aponta que a crise da teoria teria começado com os neopragmáticos Steven Knapp e Walter Michael Miller Jr. e o texto Against Theory. Esses dois teóricos teriam oposto Peirce a Saussure. Fry aponta que o problema para os outros dois autores é que seria um erro separar linguagem e discurso, significado e intenção, e que essas separações seriam responsáveis por desvirtuar a teoria. Mas aqui, também é claro que contra a teoria, para os autores, não é contra toda a teoria, é contra aquelas que se inspiraram, de uma forma mais ou menos intensa, em Saussure. Ou seja, tudo aquilo que Eagleton denominou de "teoria cultural". Na verdade, Knapp e Michael seriam a favor, por exemplo, da narratologia, estilística e toda outra abordagem que se caracterizaria mais pelo empirismo do que pela reflexão. Por mais que eu considere que Knapp e Miller Jr. tenham sequestrado para si a noção de teoria e excluído sua acepção original de teoria como reflexão, cito aqui a leitura de Fry por este apontar esse texto como sinônimo da origem da crise. Essa versão da crise pode ser entendida como a tentativa de (re)instauração da teoria com uma faceta pragmática e empírica contra uma teoria que seria exclusivamente reflexiva.

Essa interpretação, contudo, acarreta uma questão de construção binária, isto é, teoria reflexiva de um lado e pesquisa empírica do outro, sendo que o principal problema que podemos encontrar em Knapp e Miller Jr. seria a afirmação de que toda teoria é exclusivamente reflexiva e não empírica, ao passo que se deveria buscar uma pesquisa que fosse exclusivamente empírica. Isso só seria possível afirmar caso fosse possível, por um lado, fazer uma pesquisa empírica sem nenhum tipo de reflexão, o que não acontece nem na ciência mais dura, ou, por outro, 
realizar uma teoria sem objeto. A própria ideia de teoria da literatura pressupõe um objeto: a literatura (que pode, sim, ter uma definição mais ou menos ampla). O problema talvez seja que, em determinado discurso teórico, a ênfase no objeto teria sido esvaziada, mas não por completo, ou dever-se-ia ter indicado quem cometeu os abusos da teoria. Enfim, o condenável, para Knapp e Miller Jr., seria o narcisismo de certas pesquisas da teoria da literatura que teriam abandonado o objeto de estudo. Os autores, entretanto, não apontam os responsáveis por tal ato.

Mas é importante salientar a perspectiva que o par adota em contraponto com Eagleton. Se este denominou toda a "teoria cultural" como herdeiras, em alguma medida, de Saussure, os autores apenas mudam o lado do disco e defendem uma perspectiva de Peirce. É certo que a narratologia que eles chegam a elogiar é também herança de Saussure via estruturalismo literário francês. Ora, o que se tem aqui, se não uma clara disputa entre duas contratradições inventadas? Uma com origem em Saussure e outra com origem em Peirce? As traduções dessas teorias na contemporaneidade, por alguns autores, apontam que a complexidade teórica foi deixada de lado para se estabelecer um binarismo: teóricos versus empiristas. A crise, aqui, claramente, seria um discurso contra certa tradição teórica que é acusada, repetidamente, de falta de empirismo.

A pesquisa teórica nunca deixou de ser, em parte, também empírica. Ou seja, esse tipo de pesquisa não elimina a possibilidade de ser empírico. É possível colher um número absurdo de trabalhos que são teóricos e empíricos, dos mais diversos matizes, como, por exemplo, Como é Feito o Capote de Gogol de Boris Eikhenbaum; Dialética da Malandragem de Antonio Candido; ou o texto Dancing Though the Minefield de Annette Kolodny. Claro, um nível teórico pode ser sobressaltado em determinado estudo e o nível empírico em outro. Porém, não se deveria totalizar e criar certo tipo de binarismo que dificilmente poderia ser sustentado. Muitos dos teóricos da crise, como é o caso de Fry, não deixam claras suas posições ideológicas como o faz Eagleton e, em alguma medida, constrói uma contratradição inventada que exaspera a contradição: se, por um lado, a tradição que tentam reconstituir é a de uma mistura entre teoria $e$ empirismo, a teoria que negam é, por sua vez, teórica e empirista.

Peter Sloterdijk afirma que para existir uma teoria pura seria necessário, "ao menos temporariamente, suspender a fixação na real existência do agente, mesmo que isso não completamente dissolvesse 
isso [a fixação]". ${ }^{9}$ Ou seja, uma teoria pura só poderia acontecer quando o agente se suspendesse do mundo. Sloterdijk irá problematizar essa questão e indicar uma série de questões filosófico-científicas que pode ser entendida como uma espécie de crítica da razão neutra. Essa crítica seria composta por um largo grupo de teorias e filósofos que, desde a modernidade, teriam matado essa razão neutra - ou teoria pura. Uma dessas correntes "assassinas" - termo de Sloterdijk - seria a teoria feminista, ${ }^{10}$ por determinar que "a materialidade do mundo físico deveria sempre depender dos efeitos de poder culturalmente específicos". ${ }^{11}$ Nesse sentido, as teorias feministas seriam responsáveis por fazer com que a ideia de teoria pura fosse limada de dentro de nossa ideia de razão, por exemplo.

Colocando em perspectiva os discursos sobre a crise da teoria - Fry, Eagleton, Bordwell e Leitch - fica claro que a disputa por uma tradição evidencia a oposição, muitas vezes falsa, entre nós e eles, entre empirismo e teoria, entre ciência e cultura e assim por diante. As traduções dessas teorias e as contratradições inventadas, muitas vezes, acabam por ocultar e parcializar uma problemática mais ampla que as teorias desenvolveram.

\section{"Quantos somos?"}

Na crise da filosofia estudada por Husserl na década de 1930, em The Crisis of European Sciences and Transcendental Phenomenology, ele descrevia uma crise do espírito europeu, afirmando que uma das maneiras de superação da crise da ciência e da filosofia seria provar que o pensamento europeu seria, de fato, superior aos outros e, por isso, teria conquistado o resto do mundo. Husserl afirma que a luta de seu tempo era entre uma humanidade que já colapsou e uma humanidade que tenta manter suas raízes. A filosofia teria como objetivo a busca por uma verdade própria, com um sentido genuíno, ou, como ele prefere, "humanidade genuína". Seria também uma disputa entre a ideia de um telos "acidental" de várias civilizações e histórias e o telos da

\footnotetext{
${ }^{9}$ SLOTERDIJK. The Art of Philosophy, p. 17.

${ }^{10}$ As outras são o marxismo, Nietzsche, Lukács, Heidegger, física atômica, Kierkegaard/ Sartre, Foucault, Neurologia, Latour.

${ }^{11}$ SLOTERDIJK. The Art of Philosophy, p. 92.
} 
"humanidade grega" que teria se tornado essencial para a humanidade. Segundo Husserl, essa última disputa supracitada, se justificaria por ter acontecido no mundo uma "europeização" da ideia de humanidade, que indicaria que a filosofia ocidental seria o caminho natural para a vocação filosófica. Enfim, seria a filosofia "universal" europeia que deveria ser justificada nessa crise.

Derrida, em The Problem of Genesis in Husserl's Philosophy, estuda longamente o conceito de origem de Husserl. Mas gostaria de frisar, especificamente, a problemática apontada por Derrida, em que Husserl entenderia que só na Europa haveria uma "teleologia imanente" contra o resto do mundo, que seguiria uma lógica do "empirismo sociológico", com o seu telos "acidental". Nesse sentido, para Husserl, somente a Europa poderia ter constituído e desenvolvido a filosofia ocidental que teria conquistado outros territórios e dominado o mundo. O primeiro ponto é que, quando Husserl afirma que a filosofia é um fenômeno helenístico, localizado em um tempo e espaço real, reduziria a filosofia a um fato, não a um conjunto deles. O segundo ponto de Derrida é que, se for levada a sério a divisão descrita acima, teríamos um paradoxo: "ao querer descriminar absolutamente entre o sentido empírico da ideia e seu sentido transcendental, a finalidade teleológica que se quer manter absolutamente pura é transformada em uma finalidade empírica". ${ }^{12}$ Um terceiro ponto é que não seria possível distinguir rigorosamente constituição empírica e constituição transcendental, já que seriam inseparáveis. Nesse sentido, Derrida irá entender que a crise não foi mais profunda porque não haveria uma razão teleológica para a crise e porque a crise não nos revelaria nada original.

A crise dessa filosofia europeia, como entenderia Derrida, só faria sentido caso o surgimento da filosofia fosse somente um fato e não um conjunto de fatos e teleologias e transcendentais, ou que a origem de teleologias e de transcendentais não fosse mais do que fatos empíricos. Se todo o pensamento do mundo fosse reduzido ao pensamento ocidental (e à supremacia deste pelos demais), ou a) não existiria espaço para uma crise ou b) seria impossível sustentar que a crise é originalmente e

12 "by wanting to discriminate absolutely between the empirical sense of the idea and its transcendental sense, the teleological finality which one hope to keeps absolute pure is transformed into an empirical finality" (DERRIDA. The Problem of Genesis in Husserl's Philosophy, p. 158, tradução minha.) 
somente a respeito da supremacia do pensamento europeu. Se há uma crise, como afirmada por Husserl, ela não poderia ser entendida como originária de algum lugar específico e a dicotomia entre pensamento ocidental e oriental não poderia existir para que exista crise. Por outro lado, o que podemos argumentar, a partir de Derrida, é que se existe uma crise da filosofia e da ciência, ela não poderia ser universal, somente local e de um determinado tipo de pensamento e não da filosofia e da ciência, já que a própria "filosofia" já não mais seria um universal e sim uma crise de uma das tradições do pensamento, ou seja, a europeia. Dito isto, ressalta-se que o discurso a respeito das crises da teoria é um discurso de origem europeia e anglo-saxã, como fica claro nos teóricos aqui citados.

A cruzada, para justificar a teoria europeia (no tempo de Husserl) ou a teoria europeia e anglo-saxônica (na atualidade) sobre todas as outras - e aqui é importante o discurso das mulheres, dos gays e lésbicas, dos negros, dos índios, dos expatriados, dos viventes do Terceiro mundo, que não se viam celebrados por essas teorias - não justifica que o mundo passa por uma crise teórica, mas que, talvez, esse antigo império passe por ela. Enfim, seria possível afirmar de uma crise teórica da Europa e do mundo anglo-saxão, mas não necessariamente de uma crise teórica mundial.

Isso se torna bastante evidente quando nos deparamos com a discussão sobre a crise teórica fora do contexto europeu, como é o caso das discussões no Brasil. Dois exemplos podem ser significativos: o A Teoria em Crise, de Eneida Maria de Souza e o Teoria (literária) americana, de Fabio Akcelrud Durão. Este percebe que a teoria hoje é "resultado de uma exacerbação dos metadiscursos da teoria literária, que agora passam a constituir um campo (semi)autônomo"13 que, entendido de forma radical, acaba por ocupar o lugar do próprio objeto de estudo, isto é, a literatura. Entretanto, o esgotamento da teoria que prezava pela análise dos objetos faz com que ela se transforme em um aparato ideológico, sendo mais importante o objeto de estudo - sobretudo se ligado à movimentos inclusivos -, do que a sua leitura que se realizaria desse objeto e seria justamente na leitura que a crise da teoria se expressaria de modo significante. Isso aconteceria, no contexto estadunidense (e no brasileiro, mas de forma ainda não tão perversa) pela exigência cada vez maior de produtividade. Assim, a teoria seria sintoma do nosso tempo,

${ }^{13}$ DURÃO. Teoria (literária) americana, p. 13. 
cada vez mais acelerado. Durão vai propor duas possibilidades para a teoria voltar a ser significativa: a primeira, é a proposta de análise da teoria como se analisa uma obra literária e, ao mesmo tempo, retornar às obras literárias para que delas se emerja uma teoria. Em outro texto, Durão vai ressaltar a inadequação do produtivismo acadêmico em terras brasileiras:

a crescente disciplinarização e fragmentação dos campos de estudo ("studies" tornando-se uma espécie de sufixo delimitador); a quantificação, ou, melhor, a necessidade de mensurar e comparar; a fúria avaliadora; a burocratização da rotina acadêmica - tudo isso deriva, ao menos em parte, do transplante de uma certa concepção de ciência para os estudos literários. ${ }^{14}$

E ainda acrescenta que boa parte da pesquisa desenvolvida no Brasil peca por uma ânsia de aplicação de conceitos em voga, obstruindo o conhecimento da própria literatura: "a literatura não sabe nada de si; ela é toda ignorância e passividade, ao passo que a teoria, instrumento por excelência, não possui espessura, e é toda luz". ${ }^{15}$ Assim, a saída para a conclamada crise da teoria seria ao mesmo tempo "social", já que implicaria em um combate a um modelo de produtividade imposto pelo modelo econômico e, por outro lado, seria possível se voltasse a ter relevância a própria literatura, entendendo-a como um espaço do conhecimento e do saber.

Retomando perspectivas adotadas nos estudos literários no Brasil, Eneida Maria de Souza chega à crise contemporânea apontando a diluição do objeto de análise como seu ápice. Souza, entretanto, relembra que a crise teórica não é uma crise exclusiva da teoria da literatura, mas um abalo no conhecimento que acontece com a crescente diluição das fronteiras disciplinares. A teórica percebe algo que foi discutido acima, de que "a defesa de uma teoria que poderia se impor como única e exclusiva não se sustenta mais no atual espaço acadêmico, pela tendência plural das tendências críticas"16 e aposta na interdisciplinaridade que, "de grande vilã da história poderia receber tratamento mais condizente com sua força

\footnotetext{
${ }^{14}$ DURÃO. Burrice acadêmico-literária brasileira, p. 31 .

${ }^{15}$ DURÃO. Burrice acadêmico-literária brasileira, p. 31.

${ }^{16}$ SOUZA. A teoria em crise, p. 72-73.
} 
de aglutinação de diferenças e de pulverização dos limites fechados dos campos teóricos". ${ }^{17}$ Assim, Souza aponta para um futuro da teoria que é traçado já no presente, um futuro que aglutinaria diversas formas de pensamento, pluralista e que entende que a dissolução da teoria "dura", a da crise, é, na verdade, uma espécie de salvação.

Pode-se observar que a crise teórica que se dá no contexto dos países hegemônicos encontra respostas e saídas criativas nos países ditos emergentes, colocando em xeque a supremacia europeia-americana do discurso (da crise) teórico e encontrando, por aqui e nos outros países do dito terceiro mundo, uma teoria menos preocupada com seus impasses do que com soluções para que o pensar não se interrompa. Aos dois teóricos brasileiros supracitados, poderíamos acrescentar outros: Josefina Ludmer e suas considerações sobre as temporalidades latino-americanas, Leda Maria Martins e seu conceito de oralitura, Diana Klinger e as reflexões sobre a ética na e da literatura, Sandra Goulart e a diáspora literária, Hugo Achugar e o balbucio teórico latino-americano e assim por diante.

Nesse sentido, a obra de Spivak, Death of a Discipline é significativa, principalmente em sua reflexão sobre o que seria o "planetário", pensando em uma nova coletividade "que deve ser aberta com a pergunta 'Quantos somos?', quando a origem cultural é destranscedentalizada em ficção - a tarefa mais difícil na diáspora". ${ }^{18}$ Spivak vai, justamente, combater a posição centralizadora de hegemonia do lugar de enunciação. Ou seja, a coletividade deve ser pensada de uma maneira muito mais radical do que apenas o eu em relação aos outros ou no exemplo dela, a "nossa américa" em relação ao mundo. Ela clama por uma responsabilidade coletiva, percebendo que essa coletividade, tomada radicalmente, enuncia a pergunta de quantos somos.

Aqui, frisa-se que o discurso da morte da disciplina (Spivak se refere à Literatura Comparada) não é o momento do "fim" ou "depois" da teoria, mas uma oportunidade para que se repense a teoria, ou, em outras palavras, ela está muito mais interessada no renascimento da disciplina do que em seu enterro, mas um renascimento não mais colonizador. Em certo sentido, essa crise da Literatura Comparada seria uma oportunidade

\footnotetext{
${ }^{17}$ SOUZA. A teoria em crise, p. 73.

18 "that must be opened up with the question "How many are we?" when cultural origin is detranscendentalized into fiction - the toughest task in the diaspora" (SPIVAK. Death of a Discipline, p. 102, tradução minha.)
} 
para a superação de antigos problemas ao invés de um estancamento. Enfim, Spivak parece compartilhar a posição tomada acima: a de que a crise é de um paradigma local que, durante muito tempo, foi tomado como global.

\section{Fantasma da Teoria}

Judith Butler, John Guillory e Kendall Thomas, no prefácio do livro What's Left of Theory, afirmam que "a teoria não acabou, mas não é mais, se é que já foi, inteira". ${ }^{19}$ A colocação desses teóricos talvez seja a percepção mais clara do que dizíamos anteriormente: a teoria, por si só, não acabou, mas ela não apresenta mais uma unidade. Nesse sentido, dizer da antiga sensação que Eagleton observa a respeito do florescer gracioso da teoria cultural em que existiria uma torrente teórica inescapável, que, hoje, não apresenta mais a mesma hegemonia.

A teoria, nesse sentido, não acabou, mas criou uma enormidade de contratradições inventadas que, através da repetição, celebram a separação entre as mais diversas correntes crítico-teóricas, mesmo quando as traduções parecem querer ressaltar mais um aspecto do que outro na teoria, mesmo quando as fronteiras são muito difíceis de delimitar, mesmo quando essas tradições parecem fagocitadas em outras, mesmo quando essa separação se dá mais por motivos extrateóricos do que por teóricos em si.

Josué Harari, em Nostalgia and Critical Theory, destaca que a questão da teoria, de Blanchot até Derrida, de Freud a Lacan, de LéviStrauss a Girard - e o problema da literatura, desde Proust até Beckett -, seria a nostalgia pelo real. Harari acrescenta que "a noção de totalidade, ou de fechamento, que geralmente acompanha a teoria é um dos fantasmas que servem para satisfazer nossa demanda metafísica de uma retenção global e integral do real. É um fantasma da totalidade, a teoria cobre a falta do real que se inscreve no centro de nossa modernidade". ${ }^{20}$ Mas o que

19 "theory is not over, but is no longer, if it ever was, in one piece" (BUTLER; GUILLORY; THOMAS. Preface, p. XI, tradução minha.)

20 "the notion of totality, or of closure, that generally accompanies theory is one of the phantasms that serves to satisfy our metaphysical demand for a global and integral hold on the real. It's a phantasm of totality, theory covers up the lack of the real that is inscribed at the center of our modernity" (HARARI. Nostalgia and Critical Theory, p. 192, tradução minha.) 
seria esse real, ou melhor dizendo, essa "falta" do real? O real, entende Harari, "é o que é impossível de entender, pelo menos no discurso da teoria como o conhecemos hoje". ${ }^{21}$

O real, a busca pelo real, a falta do real. A constatação de que algo, agora, falta e que se busca esse pedaço faltoso. Esse real que falta é que subscreve o fim da totalidade. Assim, a crise - se tomada no sentido de separação - não é singular e única, porque a falta da totalidade do real seria a própria teoria. Não existe uma crise, ou $a$ crise. Mas uma multiplicidade de crises que justifica a afirmação de que há um momento de separação - que também é de continuidade, que também não projeta fronteiras fixas -, hoje, através das diversas contratradições inventadas. Paradoxalmente, o apontamento para várias crises ajuda a construir a crise em si. Mas, nesse sentido, não seria o caso de dizer que toda teoria é, em si, uma crise?

As contratradições inventadas da teoria apontam para uma multiplicidade de formas de se pensar a história da teoria e a crise contemporânea. Muitas dessas tradições aparecem como farsa. A querela entre teoria e empirismo - uma das maiores contratradições inventadas - seria a farsa das distinções entre ciência e cultura, primeiramente encenadas no Formalismo Russo, por exemplo; ou a disputa de discursos sobre o autor - como é exemplar o caso de Barthes - desemboca na constituição daquilo que poderia ser uma tradição, mas que se transforma em contratradição.

Ora, a pensar a teoria da literatura como uma ciência pura, objetiva e empirista é uma reencenação do velho problema colocado na própria constituição daquilo que é chamado de fundação dos estudos literários. Entretanto, essa nova encenação encenaria os mesmos problemas que anteriormente aconteceram na própria teoria, isto é, aquele algo que escapa a esses estudos que não cabe em um processo mimético entre ciências objetivas e ciências humanas e estudos literários. A fundação própria da teoria literária aponta para um caminho que se tornará inescapável ao longo de sua trajetória: uma inescapável pulsão de ser, ao mesmo tempo, empírico $e$ teórico.

Derrida refundou uma reflexão sobre o fantasma - e, quando se fala do fantasma, se fala também do luto, segundo ele mesmo -,

21 "is that which is impossible to grasp, at least in the discourse of theory as we know it today" (HARARI. Nostalgia and Critical Theory, p. 193, tradução minha.) 
justamente quando começa a falar do indesconstrutivel de Marx: "após o fim da história, o espírito vem ao revir, ele figura ao mesmo tempo um morto que revém e um fantasma cujo retorno esperado se repete, mais e mais". ${ }^{22} \mathrm{O}$ desarranjo pelo qual passa a teoria hoje poderia ser porque "o que parece quase impossível é sempre falar do espectro, falar ao espectro, falar com ele, logo, e principalmente, fazer ou deixar falar um espírito". ${ }^{23}$ Segundo Derrida, "teóricos ou testemunhas, espectadores, observadores, eruditos e intelectuais, os scholars acreditam que basta olhar. Por isso, eles já não se encontram sempre na posição mais competente para fazer o que é necessário, falar ao espectro". ${ }^{24}$ Dessa forma, Derrida decretará que é necessário pensar tanto a possibilidade do espectro quanto o espectro enquanto possibilidade.

Falar com o espectro é também falar com o passado. O luto é em relação ao passado, a perda da totalidade é em relação ao passado, algo que ali estava e não está mais. Mais uma vez, uma origem de totalidade é buscada para lidar com a história da teoria. A tradução mítica de uma teoria andrógina, outrora um uno, agora partida. As contratradições inventadas da teoria parecem querer afugentar os fantasmas, este ser que volta e insiste em voltar, desfazendo a ilusão da totalidade daquele passado construído. A possibilidade do espectro ou o espectro como possibilidade, aqui, é a tentativa de desobstruir as histórias da teoria calcadas num senso comum, em uma história que se quer naturalizada, mas que, entretanto, é construída.

Tudo o que foi discutido aqui pode soar um pouco pessimista, ou, dizendo de outra maneira, pode soar como uma arapuca que a teoria armou para si mesma. Porém, Gilles Deleuze e Felix Guattari afirmam que

Traduzir não é um ato simples; não basta substituir o movimento pelo espaço percorrido, é preciso uma série de operações ricas e [...] Traduzir é uma operação que, sem dúvida, consiste em domar, sobrecodificar, metrificar o espaço liso, neutralizá-lo, mas consistente, igualmente, em proporcionar-lhe um meio de propagação, de extensão, de refração, de renovação, de impulso, sem o qual ele talvez morresse por si só: como uma máscara, sem a qual não

\footnotetext{
${ }^{22}$ DERRIDA. Espectros de Marx, p. 26.

${ }^{23}$ DERRIDA. Espectros de Marx, p. 27.

${ }^{24}$ DERRIDA. Espectros de Marx, p. 27.
} 
poderia haver respiração nem forma geral de expressão. A ciência maior tem perpetuamente necessidade de uma inspiração que procede da menor; mas a ciência menor não seria nada se não afrontasse as mais altas exigências científicas, e se não passasse por elas. ${ }^{25}$

As traduções da teoria, caso renunciem às repetições senso comum de certas contratradições inventadas, podem ser percebidas como essa árdua tarefa da tradução, proporcionando a propagação, a expansão, a renovação e o impulso para que não abandonemos o pensar: essa é a vitalidade das teorias. A ciência "menor" da teoria literária há de continuar a afrontar as "maiores" como um fantasma.

\section{Referências}

BUTLER, Judith; GUILLORY, John; THOMAS, Kendall. Preface. In: . (org.). What's Left of Theory?. Nova York; Londres: Routledge, 2000, p. VIII - XI.

CARRIÈRE, Jean-Claude; ECO, Umberto. Não contem com o fim dos livros. Tradução de André Telles. São Paulo: Record, 2010.

DELEUZE, Gilles; GUATTARI, Felix. O liso e o estriado. In: Mil Platôs: Capitalismo e Esquizofrenia. Tradução de Peter Pál Pelbart. São Paulo: Ed. 34, 2008. v. 5, p. 179-214.

DERRIDA, Jacques. Espectros de Marx: o estado da dívida, o trabalho do luto e a "nova Internacional". Tradução de Anamaria Skinner. Rio de Janeiro: Relume-Dumará, 1994.

DERRIDA, Jacques. The Problem of Genesis in Husserl's Philosophy. Tradução de Marian Hobson. Chicago; Londres: Chicago University Press, 2003. Doi: https://doi.org/10.7208/chicago/9780226143774.001.0001.

DURÃO, Fabio Akcelrud. Burrice acadêmico-literária brasileira. Revista da Anpoll, [S.l.], v. 1, n. 43, 2017. Doi: https://doi.org/10.18309/anp. v1i43.1053.

DURÃO, Fabio Akcelrud. Teoria (literária) americana: uma introdução crítica. Campinas: Autores Associados, 2011.

${ }^{25}$ DELEUZE; GUATTARI. O liso e o estriado, p. 194-195. 
EAGLETON, Terry. Depois da teoria. Tradução de Maria Lucia Oliveira. Rio de Janeiro: Civilização Brasileira, 2011.

FRY, Paul H. Theory of Literature. New Haven: Yale University Press, 2012.

HARARI, Josué. Nostalgia and critical theory. In: KAVANAGH, Thomas M. The Limits of Theory. Stanford: Stanford University Press, 1989. p. 168-193.

HOBSBAWN, Eric; RANGER, Terence. A invenção das tradições. Tradução de Celina Cardim Cavalcante. São Paulo: Paz e Terra, 1997.

HUSSERL, Edmund. The Crisis of European Sciences and Transcendental Phenomenology. An Introduction to Phenomenological Philosophy. Tradução de David Carr. Evanston: Northwerstern University Press, 1970.

LEITCH, Vicent B. Living with Theory. Malden: Blackwell Publishing, 2008.

SLOTERDIJK, Peter. The Art of Philosophy: Wisdom as a Practice. Tradução de Karen Margolis. Nova York: Columbia University Press, 2010.

SOUZA, Eneida Maria de. A teoria em crise. In: . Critica cult. Belo Horizonte: Ed. UFMG, 2007. p. 63-74.

SPIVAK, Gayatri Chakravorty. Death of a Discipline. Nova York: Columbia University Press, 2003.

SÜSSEKIND, Flora. A crítica como papel de bala. In: AMARAL, Sérgio Alcides Pereira do; CORDEIRO, Rogério; SOARES, Claudia Campos; WERKEMA, Andréa Sirihal. A crítica literária brasileira em perspectiva. Cotia: Ateliê Editorial, 2013, p. 274-278. 